\title{
Ubiquinone 10 Measurement
}

National Cancer Institute

\section{Source}

National Cancer Institute. Ubiquinone 10 Measurement. NCI Thesaurus. Code C147321.

The determination of the amount of ubiquinone 10 present in a sample. 